\title{
WAYS OF REDUCTION OF POLLUTION OF AN ENVIRONMENT BY SHIP POWER INSTALLATIONS
}

\author{
Andrei V. Ivanov, \\ Valery A. Petuchov \\ Admiral Makarov State Maritime Academy, Russia
}

\begin{abstract}
In the report are discussed ways of reduction of pollution of an environment by ship power installations. Among them it is necessary to select optimization of regimes of operations of main traditional ship sources of the electric power, the installation of systems of utilization of refuse energy of the exhaust gases and cooling water from main and auxiliary engines, application of new types of sources of the electric power and the using of complex automation and control systems for exhaust gases and for selecting of regimes main engine, auxiliary engine, utilize boiler, auxiliary boiler, shaft generator.
\end{abstract}

\section{KEYWODS}

Ship, system, power installations, optimization of regimes, sources of the electric power, utilization, shaft generator, diesel, exhaust gases, turbine .

\section{INTRODUCTION}

The Baltic region is area, where the plenty water transport communications is crossed. Thousand ships plough water open spaces, being by one of sources of pollution of an environment. If the pollution of water resources is supervised and is regulated by sea international classification societies, the specifications on restriction of pollution of air environment is planned to enter only since 2000 (Fig. 1). The average total capacity of ship main diesel engines makes $5000-7000$ $\mathrm{kW}$, that are equivalent 100-150 cars capacities of engines. Thus, the problem of reduction of pollution of an environment by exhaust gases of ship engines is now rather urgent. Improving the combustion of hydrocarbons and reduce emissions, in particular of $\mathrm{NO}_{\mathrm{x}}$ without compromising on thermal efficiency, is possible by the ideal combination of compression ratio, injection timing and injection rate, in other words by increasing the compression ratio and raising the cylinder combustion pressure. The injection equipment has also been designed so that fuel is injected later 
than normal, with a short, distinct injection period, improved fuel atomisation and matching of combustion space with fuel sprays to facilitate air and fuel mix.

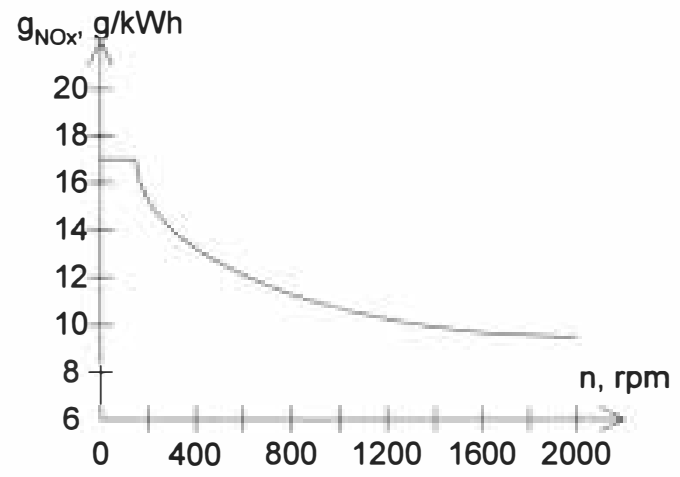

Fig. 1. International Marine Organisation proposal: $\mathrm{NO}_{\mathrm{x}}$ limit as a function of engine speed an nominal regime

$\mathrm{g}_{\mathrm{NOx}}-$ specific $\mathrm{NO}_{\mathrm{x}}$ emissions weighted, $\mathrm{n}$ - engine speed

\section{Directions for the decision of the given problem}

1. Concern for the environment is a priority at diesel. One of the primary operating objectives in the design of the diesel was to keep emission levels low. It has been proven that primary emission control is achieved by optimizing the combustion process. This is one of the advantages of modern diesel technology incorporated in the diesel - one of the most environmentally friendly engines available today. A totally new combustion process was developed, which achieves the lowest possible fuel consumption in combination with optimum output and emissions levels. An advanced fuel injection system and a specially designed combustion chamber obtain the most from measure of fuel. The full resources of the diesel group technology center were utilized to bring to fruition a new engine that is the culmination of years of diesel expertise and experience.

2. Although the diesel was specifically to operate efficiently on lower-grade fuels, the technology of its fuel injection system allows it to also accommodate natural gas or liquefied petroleum gas. This flexibility makes it one of the most fuel-versatile engines on the market today. The cost of fuel is favourably impacted by this flexibility as well.

3. The essential influence to structure of final gases renders a modification of frequency of rotation of a diesel engine. The graphs of a modification unhealthy for environment components in final gases of a diesel engine of a type 6 $4 \mathrm{H} 25 / 34$ in function of frequency of rotation are reduced on Fig. 2. From Fig. 2 it is visible, that with a diminution of frequency of rotation of a diesel engine the content unhealthy for environment component in gases considerably decreases.

4. The days are definitely past when high thermal efficiency was the only criterion for successful engine design. Today, the engine concept has to combine optimum fuel efficiency with low emissions. In this respect diesel engine exhibits outstanding performance in the market place, with an engine efficiency of $50 \%$ and a $\mathrm{NO}_{x}$ level complying with the future $\mathrm{IMO} 2000$ regulation (Fig.1). 


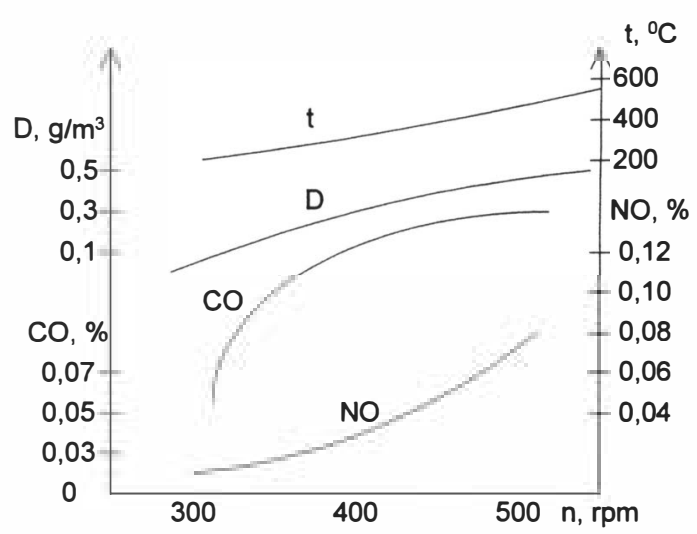

Fig. 2. The graphs of a modification of concentration unhealthy for environment components in exhaust gases of a diesel engine $6 \mathrm{HH} 25 / 34$ in functions of frequency of rotation

5. The solution for further reduction of $\mathrm{NO}_{\mathrm{x}}$ emissions with approx. $50 \%$ is to use Direct Water Injection.

6. The solution is the high engine efficiency resulting in exceptionally low emissions of carbon dioxide $\left(\mathrm{CO}_{2}\right)$, because the carbon dioxide emissions are entirely a function of the specific fuel consumption, therefore any decreasing the specific fuel consumption is the decreasing emissions.

7. $\mathrm{NO}_{\mathrm{x}}$ emissions can, however, be removed almost completely by equipping ships with SCR (selective catalytic reduction) reactors. This is already being applied in some newbuildings, and does not affect fuel consumption.

8. The variable inlet valves closing of the diesel gives a valuable reduction in smoke emissions in the low-load range.

\section{Optimisation of regimes of operations of relate a diesel engine - generating set}

Now all ship diesel engine - generating set (DGS) work on loading characteristics with keeping constant frequency of rotation in all a range of change of operations loads. Thus, as experience of maintenance ship electropower systems has shown, DGS work on share loads the overwhelming majority of time, that is accompanied by many negative factors, basic of which are the raised expenses of the fuel and oil materials, and as resul, it is an increase of pollution of an environment.The solution of the given problem is connected to transition to a new way of regulating DGS, at which the frequency of rotation is regulated as the function of load of prime engine DGS, due to what, the optimal regime of operations of a diesel engine in all a range of change of loads is supported. The using of the given mode of operations DGS is possible using the last power converter achievements and microprocessor control systems. From Fig. 3 the significant diminution of specific expenditure of fuel $\left(\mathrm{g}_{\mathrm{e}}\right)$ by a diesel engine of regulating with variable frequency is visible. 


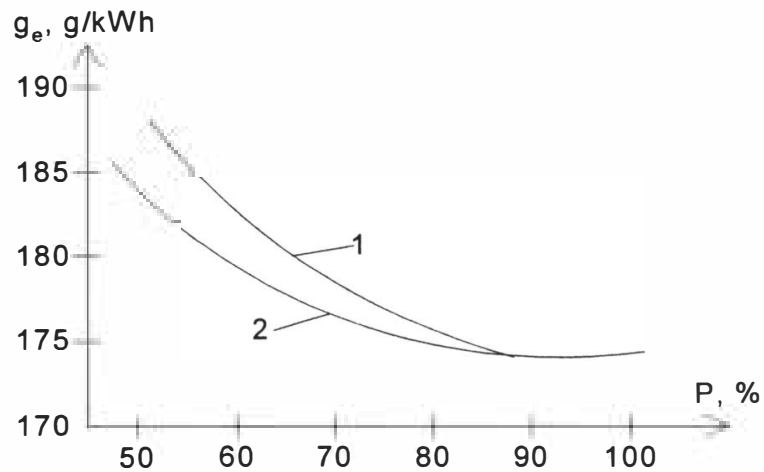

Fig. 3. Assotiation of expenditure of fuel from a load for different modes of regulating of frequency of rotation of a diesel engine firm $\operatorname{MAK}(\mathrm{P}=1000 \mathrm{~kW} / \mathrm{Cyl}) 1-\mathrm{n}=$ const, $2-\mathrm{n}=\mathrm{var}$ (on optimal low)

\section{Rise of efficiency of selection of power from main power installation with shaft generating} set

The application of a new generation control regime system in engineering solves the problem of optimization of regime of operations of the prime engine DGS on ships with controllable pitch propellers and shaftgenerators. The experimental researches conducted on a vessel of "Smolensk" have shown, what even the insignificant diminution of frequency of rotation of a prime diesel engine from 50 before $48 \mathrm{~Hz}$ gives essential saving of fuel. Contamination of an atmosphere the exhaust gases therefore decreases also. The performances of consumption of fuel for different frequency of rotation of a main diesel engine are represented on Fig.4.

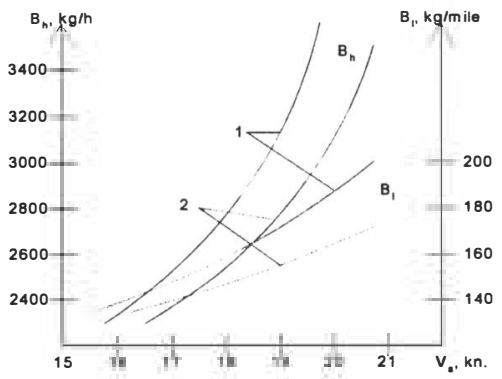

Fig. 4. Speed characteristics of a main diesel engine of a ship "Smolensk".

$\mathrm{B}_{\mathrm{h}}$ - hour consumption of fuel, $\mathrm{B}_{\mathrm{l}}$ - consumption fuel on mile. 1 - $\mathrm{n}=$ const, 2- $\mathrm{n}=$ var (on optimal low) 
In turn, the creation of new types of shafsgenerators installations on base of completely controlled semiconducting converters will allow to raise efficiency of selection of power from main engine.

\section{Utilization of refuse energy of the exhaust gases and cooling water from main and auxiliary engines}

The support of economic operation DGS on partial regimes will allow use of utilization turbogenerators (UTG) on modern ships and solve in a new fashion the problem of parallel operation UTG and DGS, by ensuring a maximum efficiency of the utilization of refuse energy of the exhaust gases of the engines. The ship electropower system with shaft generator and utilization turbo generator is showed on Fig. 5.

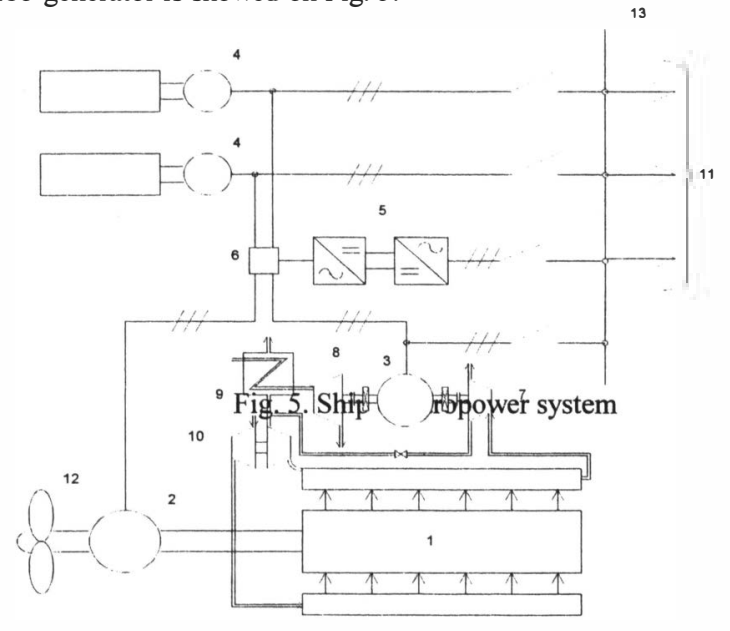

1 - Main engine, 2- shaft generator, 3 - turbo generator, 4 - diesel generator, 5 - converter of frequency, 6 - switch, 7 - utilize gas turbine, 8 - steam utilize turbine, 9 - boiler, 10 turbocompressor, 11 - electrocustomers, 12 - propeller, 13 - ship switchboard

For want of course of a ship in the sea the electric power makes utilize turbo - generator 3 , reduced in driving steam by 8 or gas turbine 7 . In case of necessity in work can participate shaft generator 2 . The main diesel engine 1 works with variable frequency of rotation. For a frequence control in a ship electrical network the semiconducting converter of frequency 5 is used, to which with the help of of switch 6 all ship radiants of the electric power can be connected. A diesel engine - generator 4 in the given installation also can work with variable frequency. The use in the given installation for production of the electric power of generators of a various type and optimization of conditions of their work allows essentially to reduce volume of completing gases of diesel engines. 


\section{New types of sources of the electric power}

A rather perspective direction of development of ship electric power industry is use of new types of sources of the electric power such as windgenerators, generating aggregates on base of flywheel disk drives, static sarve electric power.Use of the listed sources of the electric power for the electric motor, which provides movement of a vessel, will allow to create of ships practically neutral to an environment. On sailing-motor ship a source of practically free-of-charge electric power can become propeller electromotor, working, at a course of a ship under sails, in a regime of the hydrogenerator. The statistical dates, which were collected by the authors, show, that the wind force 4 and more of a at world ocean reaches more than $50 \%$ of time. It is confirmed by the diagram on Fig.6.

It is enough of a wind of such force, that the sailing ship has developed a velocity 8 and more knots. An association of a maximum power, which can be removed from the propeller working in a condition of the water-turbine, from a velocity of a ship is reduced on Fig.7. A power of electrocustomers of a sailing ship of a type "Mir" equals about 80-100 kW. The removal of such power from the propeller working in a condition of the water-turbine decreases the velocity of a vessel no more than on 1 knot, that is visible from Fig. 8. The experimental researches, conducted by the authors, on a sailing ship "Mir", from Admiral Makarov State Maritime Academy, have confirmed, that the propeller, the gyrating generator want of driving of a ship

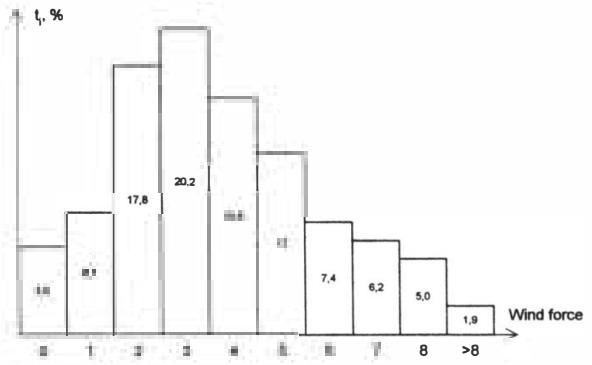

Fig. 6. Wind force at world ocean

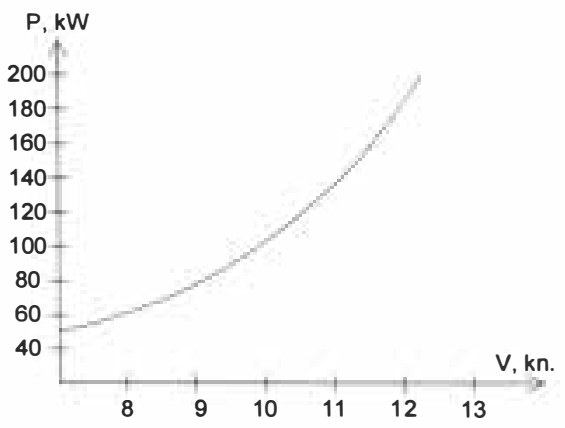

Fig. 7. Dependence of a power on the propeller from a velocity of a ship

under sails, can be a free source of an energy. The practical application specified a way of reduction of pollution of environments is connected with the solution of a problem of stabilization of electrical parameters of the ship system, that it is possible to using the last achievement of science and of engineering. 


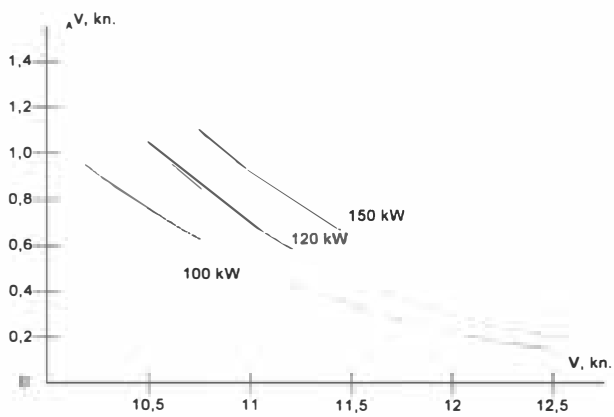

Fig. 8. Decrease of a velocity of a ship for work of the propeller in a condition of the waterturbine from ships velocity ${ }_{\mathrm{A}} \mathrm{V}$ - decrease of a velocity of a ship, $\mathrm{V}$ - velocity of a ship

\section{CONCLUSION}

The main ways of reduction of pollution of an environment by ship power installations are:

- optimization of regimes of operations of main traditional ship sources of the electric power, to which first of all is necessary to relate a diesel engine - generating set (DGS),

- rise of efficiency of selection of power from main power installation with shaftgenerating set,

- utilization of refuse energy of the exhaust gases and cooling water from main and auxiliary engines,

- application of new types of sources of the electric power.

\section{LIST OF REFERENCE}

1. Ivanov A., Vijas I. (1991). Research of work of the propeller in a regime of the water-turbine. In: Dynamics of ship power installations and their systems, Mortechinformreklama Press, St.Petersburg, pp.79-92.

2. Ivanov A., Vijas I. (1996). Welengeneratoranlage mit Cycloconverter. Technischer Bericht 21/96, TUHH Press, Hamburg.

3. Petuchov V., Ivanov A. (1998). Work of ship auxiliary diesel engine - generating set. Marine sea fleet N 2, pp. 22.

4. Petuchov V., Ivanov A., Petrov G. (1998). Optimisation of regimes of operations of relate a diesel engine - generating set of ship electropower systems. Second International Shipbuilding Conference - ISC'98, St.-Petersburg, pp. 306 - 311 